\title{
PREDICTION OF THE STRESS-STRAIN STATE OF A ROAD STRUCTURE WITH SHALLOW TRANSVERSE TUBULAR DRAINAGE
}

\author{
Olena Slavinska ${ }^{1}$, Andrii Bubela ${ }^{2}$, Oleksandr Davydenko ${ }^{3}$ \\ ${ }^{1}$ Department of Transport Construction and Property Management, National Transport University, Kyiv, Ukraine \\ elenaslavin9@gmail.com \\ ORCID: http://orcid.org/0000-0002-9709-0078 \\ ${ }^{2}$ Department of Transport Construction and Property Management, National Transport University, Kyiv, Ukraine \\ bubelaandrey@ukr.net \\ ORCID: http://orcid.org/0000-0002-5619-003X \\ ${ }^{3}$ Department of Bridges, Tunnels and Hydraulic facilities, National Transport University, Kyiv, Ukraine \\ oleksandr.davydenko@ntu.edu.ua \\ ORCID: http://orcid.org/0000-0003-0176-3256
}

ARTICLE INFO

Article history:

Received date 30.06 .2020

Accepted date 22.07.2020

Published date 31.08 .2020

Section:

Building

D O I

$10.21303 / 2313-8416.2020 .001396$

KEYWORDS

stress-strain state

road structure

shallow drainage

tubular drain

PVC pipe

concrete pipe
ABSTRACT

The stress-strain state of a road structure with shallow tubular drainage, which is arranged on waterlogged sections of public highways, has been investigated. Three-dimensional models of the road structure with pipes made of various materials were built using the finite element method. Experimental studies on models were carried out for cases of normative and over-norm load on the basis of the SCAD Office software and calculation complex. The distribution of normal stresses, deformation values in the road structure and directly in the body of the tubular drain is obtained. The working conditions were determined and the expediency of using PVC pipes and concrete pipes on the road of III category was substantiated.

Subject of research: stress-strain state of a road structure with shallow transverse tubular drainage.

Investigated problem: determination of deformations in a road structure with tubular drains based on the distribution of normal stresses.

Main scientific results: distribution of isopoles and isolines of normal stresses, deformation values in road structures with shallow transverse tubular drainage. The expediency of using the type of drainage pipes on waterlogged sections of roads under conditions of excess load has been determined.

The area of practical use of the research result: design institutions and enterprises specializing in the road transport industry.

An innovative technology product: stress and strain distribution in atypical road structures with tubular holes.

Scope of application of the innovative technological product: for the design of atypical road structures with tubular holes on waterlogged road sections.

(C) The Author(s) 2020. This is an open access article under the CC BY license http://creativecommons.org/licenses/by/4.0).

\section{Introduction}

\section{1. The object of research}

Stress-strain state of a road structure with shallow transverse tubular drainage.

\section{2. Problem description}

Shallow drainages (SD), as a rule, are arranged on waterlogged sections of public highways. In the conditions of Ukraine, drainage slots in a road structure (RS) with an estimated water consumption of more than $0.72 \mathrm{~m}^{3} /$ day are arranged only with tubular drains, according to DSTU-N B V.2.3-41:2016 "Guidelines for the design of shallow drainage structures on automobile roads". Tubular drains must operate in a free-flow mode in the RS working area, which perceives a double load from vehicles and its own weight. RS is designed as a solid spherical one, with the corresponding elastic moduli for each layer of the pavement, base and soil of the subgrade, according to GBN V.2.3-37641918-559: 2019 "Road pavement. Design”. In spring or autumn, waterlogged sections of highways (excavations, at zero marks) operate in an overloaded mode with a reduced 
modulus of elasticity of the base layers and the upper part of the roadbed. This problem is especially acute when the operating conditions of highways are overloaded with heavy vehicles. The total modulus of RS elasticity does not take into account the presence of tubular holes, and during the operation of drainage pipes, a problem arises according to the type of materials they are made of. It is important not only to determine the mode of their operation in terms of removing water from the base of the pavement, but also by their integrity, in particular, the distribution of the stress-strain state (SSS).

The work of drainage structures is mainly considered from the point of view of ensuring drainage on waterlogged sections of highways. In work [1], on the basis of a numerical experiment, the prediction of the process of water disposal by a drainage system in conditions of critical rains is presented. In [2], the dependence of the effect of vibration on the intensity of drainage of a drainage structure made of various filler materials was investigated and correlation-regression dependences were obtained to determine the intensity of drainage for each of them.

In many countries of the world, the problem of drainage from the carriageway and from the layers of the base of the road pavement of the highway remains urgent. Crushed stone or sand layers are mainly used, as well as layers of geotextile and geocomposite [3]. The selection of the parameters of tubular drainage structures is mainly carried out using the analytical method.

The assessment of the influence of the dynamic load from the vehicle on the road surface was carried out in [4], the numerical results of the dependence of the effect of vibration on the unevenness of the road surface and on the increase in the speed of traffic are presented. The load from the vehicle causes a three-dimensional stress-strain state with significant gradients of compressive, tensile and shear stresses in the multilayer massif of the road structure, as indicated in [5]. Asphalt concrete pavement resists these types of stresses in different ways and especially their combinations.

A new approach to determining the stress-strain state of a multilayer road structure weakened by tubular holes is presented in [6]. This approach makes it possible to determine the design parameters of the RS layers, in particular, the $\mathrm{SD}$, to ensure the overall bearing capacity of the road sections. A series of numerical experiments was carried out that included two types of tubular drains: PVC and concrete pipes. Different trench filling materials were modeled according to each type of pipe drain material. The results of numerical modeling made it possible to obtain diagrams of normal stresses and deformations of structural layers. The presented studies were carried out on two-dimensional models, which do not allow to fully obtain the distribution of RS SSS strength indicators.

The above analysis determines the relevance and the need for research to determine the efficiency of shallow drainage structures made of various filler materials under the vehicle influence on three-dimensional models.

\section{3. Proposed solution to the problem}

It is possible to study the RS SSS stress-strain state with transverse tubular SD on the basis of three-dimensional models in the SCAD Office software and computational complex (SCC). This will make it possible to obtain the isopoles of normal stresses and the distribution of deformations, to analyze the work on the RS itself and on several types of tubular drains.

According to the aim of the work is to predict the RS SSS stress-strain state with a transverse tubular DS made of various materials on the basis of the constructed models by the finite element method under standard and excess loads.

\section{Materials and methods}

2. 1. Nomenclature of materials for structural elements of road structures with shallow transverse tubular drainage

Numerical experimental studies were carried out for RS of highways of the III category, the length of which is the largest in Ukraine according to.

Two types of 3D models with tubular drains were built. RSs are given in Table 1 of the specified pavement layers and material characteristics.

Two types of pipes were considered as tubular SD: a PVC pipe of SN 8 (SN 4) class and a concrete pipe with an inner diameter of $100 \mathrm{~mm}$. The PVC pipe is enclosed in a subgrade trench under the drainage layer of the pavement, according to [7], and crumbled with medium-grained sand filler. The sandy layer and the trench filler (Table 1) operate in a waterlogged mode. 
Table 1

Characteristics of a road structure with a transverse tubular SD

\begin{tabular}{|c|c|c|c|c|c|}
\hline No. & Road construction layers & $\begin{array}{c}\text { Elastic modulus } \\
\mathrm{E}, \mathrm{MPa}\end{array}$ & $\begin{array}{c}\text { Layer thickness } \\
\text { h, } \mathbf{m}\end{array}$ & Poisson's ratio & $\begin{array}{l}\text { Specific weight, } \\
t / \mathbf{m}^{3}\end{array}$ \\
\hline \multicolumn{6}{|c|}{ Pavement layers } \\
\hline 1 & $\begin{array}{l}\text { Dense asphalt concrete on bitumen } \\
\text { BND 60/90, Type A, Grade I }\end{array}$ & $480 \mathrm{MPa}$ & 0.1 & 0.3 & 2.3 \\
\hline 2 & $\begin{array}{l}\text { Crushed stone-sand mixtures, reinforced with } \\
\text { M } 20 \text { cement }\end{array}$ & 400 & 0.12 & 0.3 & 2.3 \\
\hline 3 & Crushed stone-sand mixture C-5 & 240 & 0.21 & 0.3 & 2.4 \\
\hline 4 & Medium-grained sand & 116 & 0.3 & 0.3 & 2.0 \\
\hline \multicolumn{6}{|c|}{ Drainage trench No. 1} \\
\hline 5 & Medium-grained sand (trench filler) & 116 & 0.25 & 0.3 & 2.0 \\
\hline 6 & $\begin{array}{l}\text { Drainage pipe PVC SN } 8 \text { (SN 4), inner diameter } \\
92 \mathrm{~mm} \text {, outer diameter } 110 \mathrm{~mm} \text {. }\end{array}$ & 3600 & 0.11 & 0.38 & 1.4 \\
\hline \multicolumn{6}{|c|}{ Drainage trench No. 2} \\
\hline 7 & Coarse sand (trench filler) & 135 & 0.25 & 0.3 & 2.3 \\
\hline 8 & $\begin{array}{l}\text { Concrete pipe, inner diameter } 100 \mathrm{~mm} \text {, outer } \\
\text { diameter } 118 \mathrm{~mm} .\end{array}$ & 2500 & 0.118 & 0.2 & 2.3 \\
\hline \multicolumn{6}{|c|}{ subgrade } \\
\hline 9 & Silty sandy loam & 48 & 2 & 0.3 & 2.0 \\
\hline
\end{tabular}

When carrying out numerical studies on a three-dimensional model with a concrete pipe, trench filler was considered - coarse-grained sand, the modulus of elasticity of which almost does not change under conditions of waterlogging, according to [7]. The total thickness of the road pavement is $0.73 \mathrm{~m}$, the subgrade $-2 \mathrm{~m}$ (Table 1).

\section{2. Construction of a road structure model with a transverse tubular SD}

There is no generally accepted algorithm for creating a computational model in software systems based on the finite element method. When designing or a scientific experiment, each object has its own characteristics. Taking into account the design features and certain tasks, the design model may differ significantly and even have different calculation results.

To create a RS model with tubular holes, the problem arose of limiting the displacements of the soil massif at the support nodes (along the extreme edges of the massif). In works [8,9], the schemes are significantly different, although the work of the soil massif is investigated together with the bearing elements of structures. After analyzing the work, it is possible to come to the conclusion that limiting displacements along the edges of the model will significantly reduce deformations along the vertical extreme edges of the soil mass. In such a scheme, horizontal deformations will be equal to zero, respectively, and vertical ones will decrease closer to the edges of the model [8]. Similar results were obtained in [9]. Thus, it was decided to limit any movement along the horizontal edges of the model. Due to the sufficient thickness of the soil mass in the model, there is no additional effort in the area where the elms are located.

A problematic issue is the unification of a trench with a tubular element and with a continuous layered RS. At the initial stage, the construction of RS models was carried out in a three-dimensional computer-aided design and drawing system AutoCAD, which made it possible to take into account the features and parameters of structural elements, and then to adapt them in the SCAD Office environment. A section of a public highway of the III category, $3.6 \mathrm{~m}$ long, in accordance with the requirements of DBN V.2.3-4: 2015 "Highways" was considered. The model is built of rectangular elements $0.1 \mathrm{~m}$ and $0.18 \mathrm{~m}$ in size, respectively, in the transverse and longitudinal directions. The load was evenly distributed over a rectangle $0.2 \mathrm{~m}$ by $0.36 \mathrm{~m}$, which in area corre- 
sponds to a stamp with a diameter of $0.303 \mathrm{~m}$, according to [10]. In order to comply with the real RS operating conditions and according to [10], loads of the A2 type were accepted for roads with a capital type of coverage, the excess load exceeded the normative one by 1.5 times.

\section{Results of studies of the stress-strain state of a road structure with a transverse tubular SD}

Numerical experimental studies made it possible to obtain a three-dimensional distribution of isopoles and isolines of SSS strength indicators. The results are shown in Fig. 1-4. For each type of tubular drains, the general distribution of normal stresses $\mathrm{Nz}$ and deformations $\mathrm{Z}$ in the transverse profile of the road under the influence of the normative Fig. 1, 3, a, $c$ and above-standard Fig. 2, 4, a, c in loads. Fragments of the distribution of the largest normal stresses $N z$ are shown in Fig. 1-4, $\boldsymbol{b}$ and deformations $Z$ Fig. 1-4, $\boldsymbol{d}$ in the area of placement and in the body of the tubular drain.
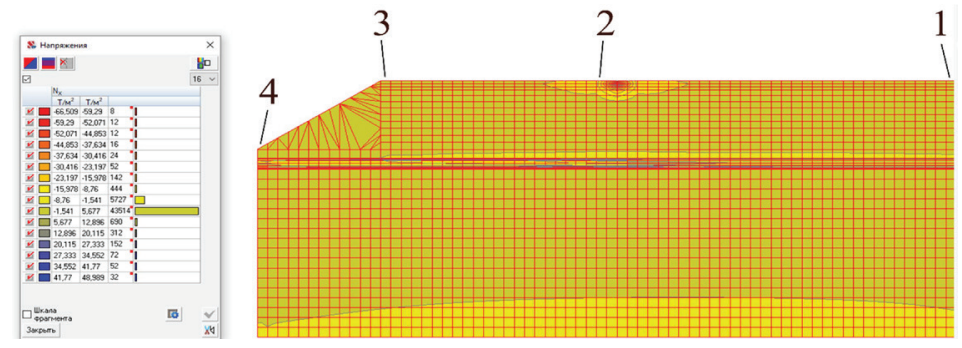

$a$

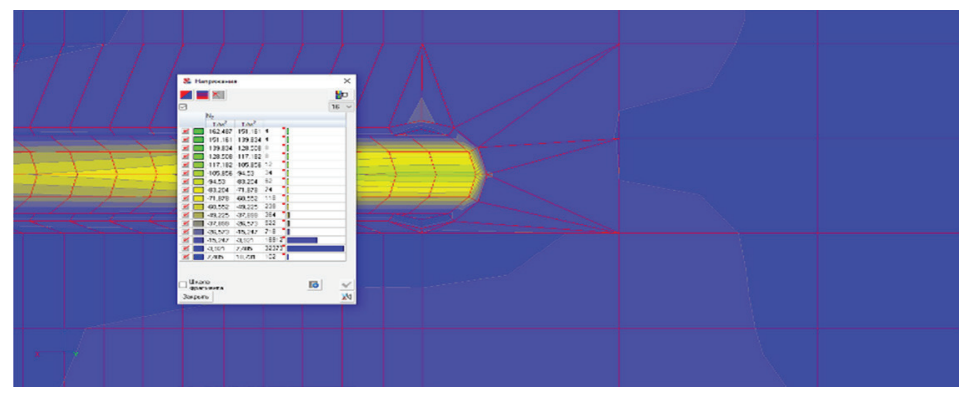

$b$

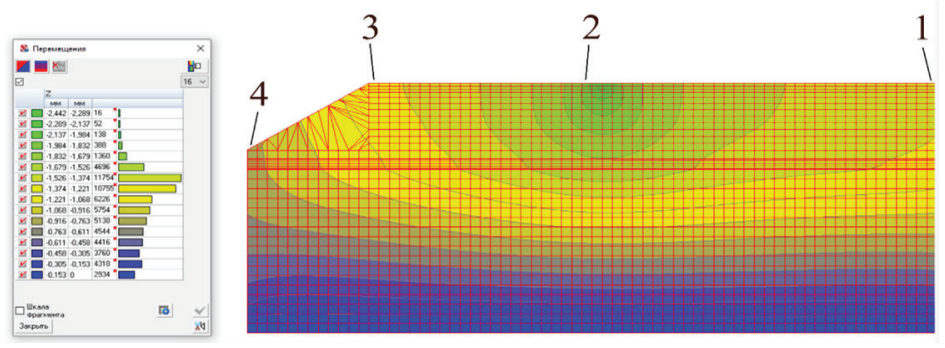

$c$

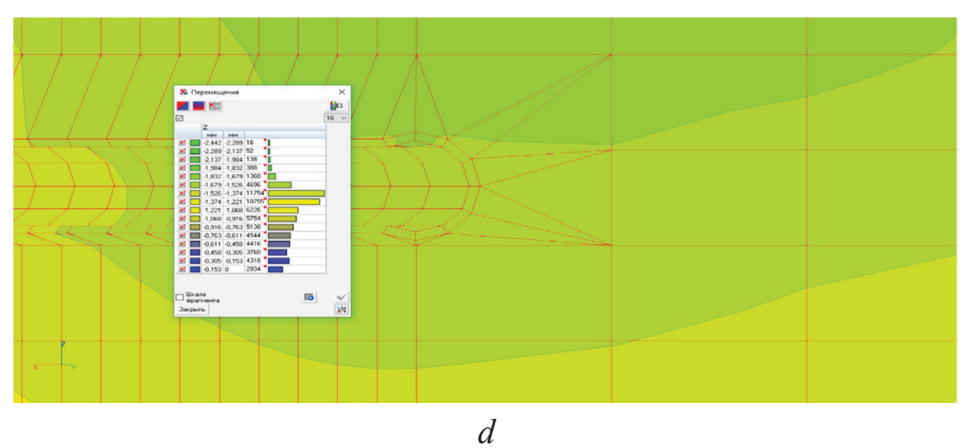

Fig. 1. Distribution of normal stresses Nz and deformations Z in a road structure with PVC pipe SN8 (SN4) from the action of a standard load of $57.5 \mathrm{kN}$ : $a$-distribution of isopoles and isolines of stresses Nz; $b-$ a fragment of the distribution of normal stresses $\mathrm{Nz}$ in the body of the drainage pipe; $c$ - distribution of deformations $\mathrm{Z} ; d$-a fragment of the distribution of deformations $\mathrm{Z}$ in the body of the drainage pipe; 1 - carriageway; 2 - load application; 3 - shoulders; 4 - slope 

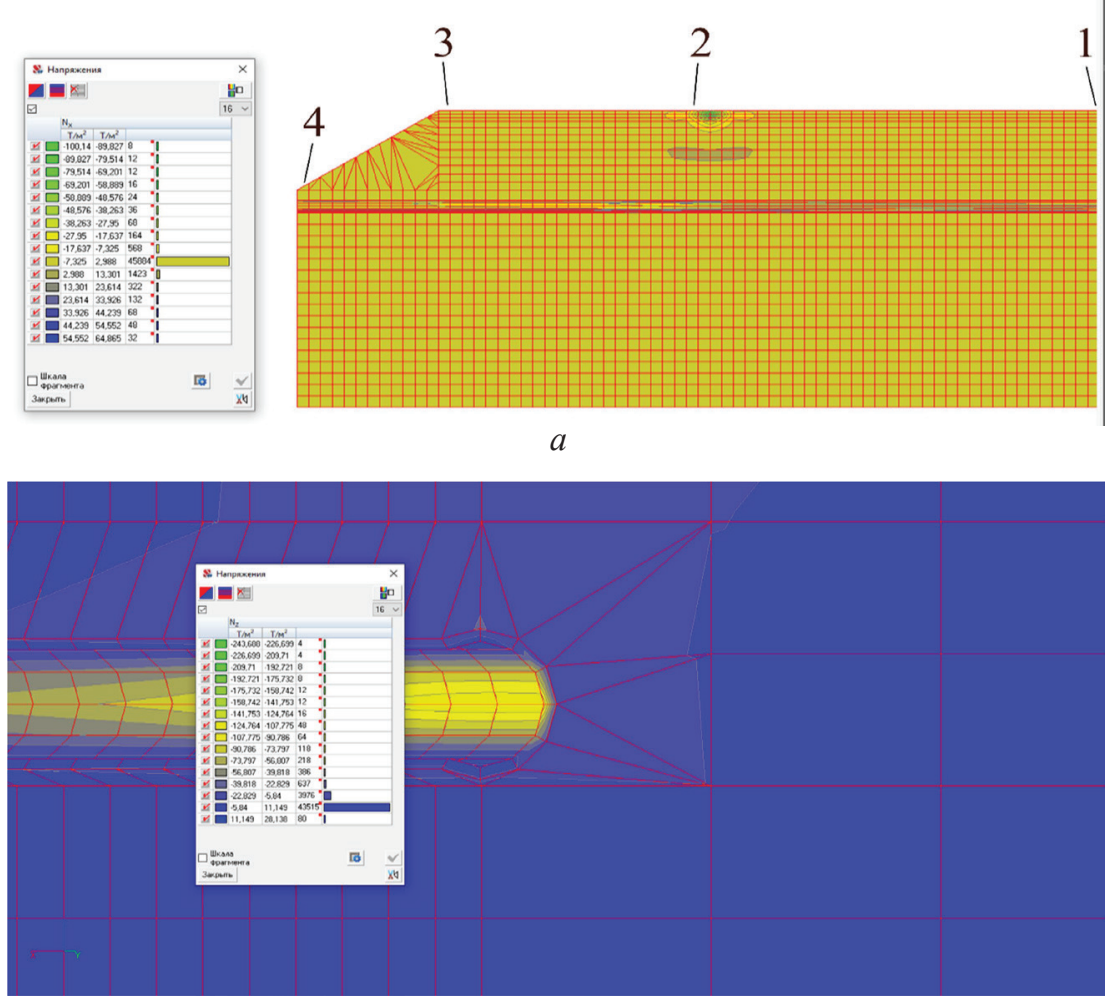

$b$
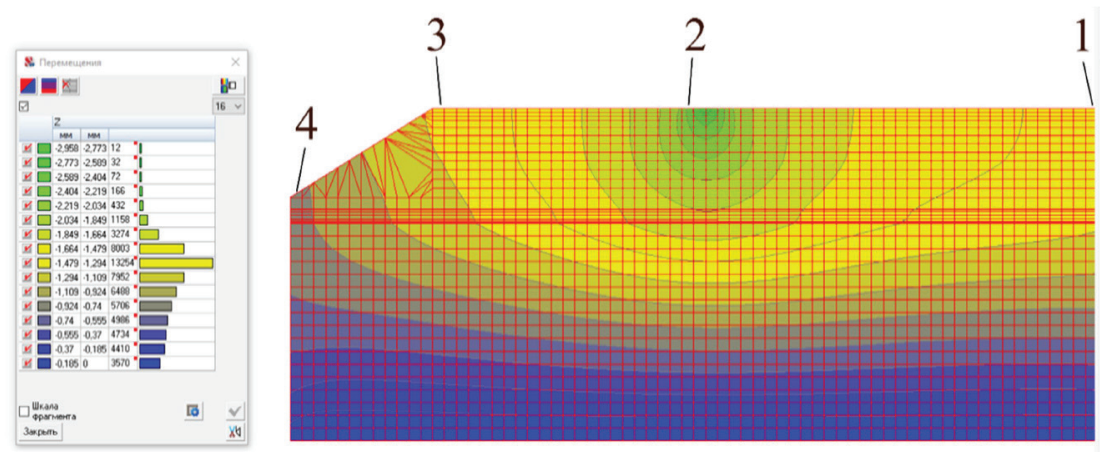

$c$

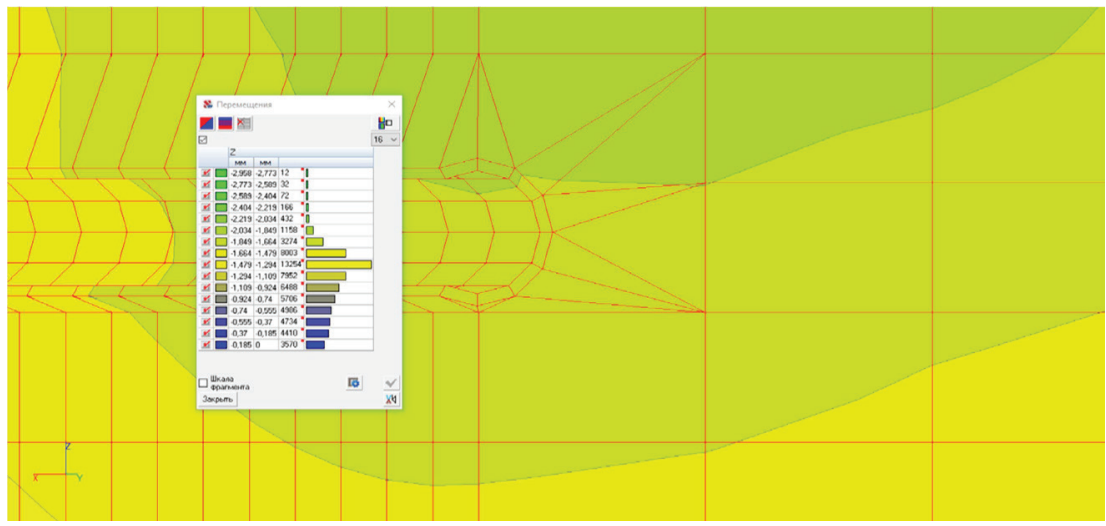

$d$

Fig. 2. Distribution of normal stresses $\mathrm{Nz}$ and deformations $\mathrm{Z}$ in a road structure with PVC pipe SN8 (SN4) from the action of a standard load of $86.25 \mathrm{kN}$ : $a$-distribution of isopoles and isolines of stresses $\mathrm{Nz} ; b-\mathrm{a}$ fragment of the distribution of normal stresses $\mathrm{Nz}$ in the body of the drainage pipe; $c$ - distribution of deformations $\mathrm{Z} ; d$-a fragment of the distribution of deformations $\mathrm{Z}$ in the body of the drainage pipe; 1 - carriageway; 2 - load application; 3 - shoulders; 4 - slope 


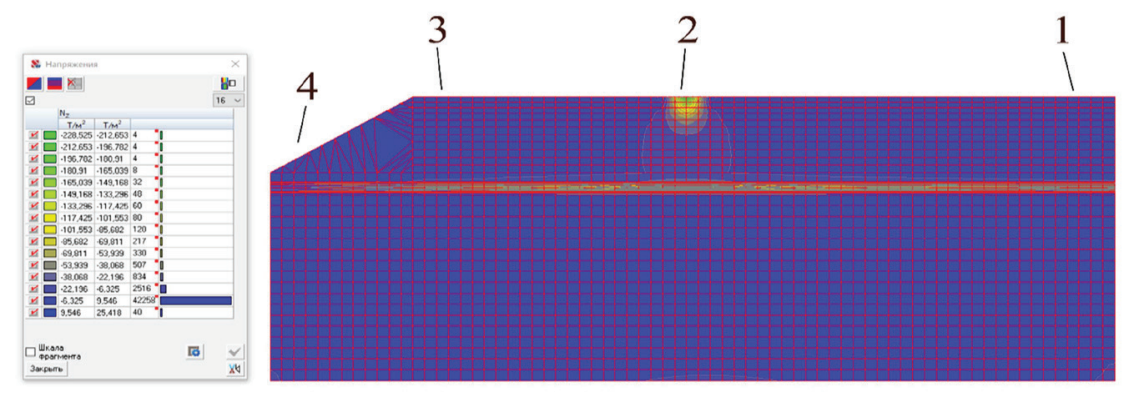

a

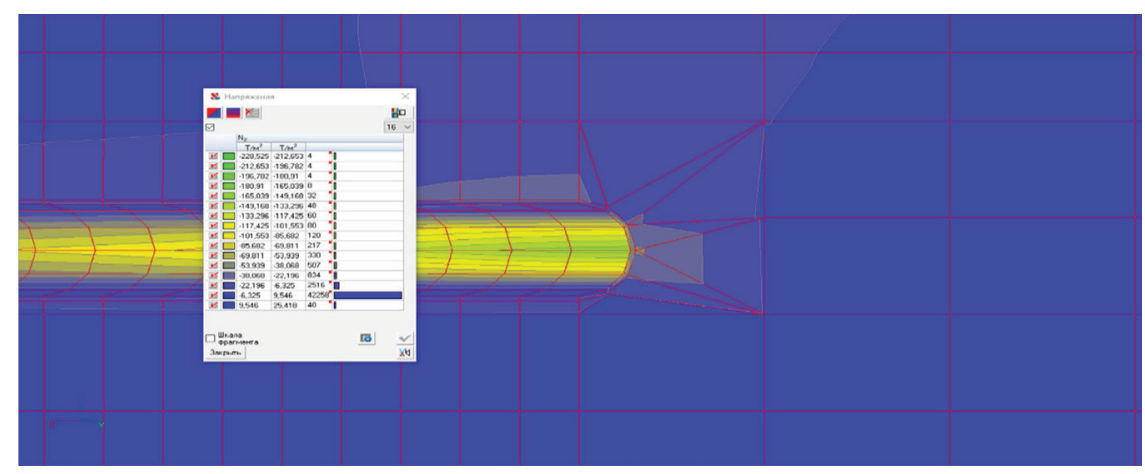

b

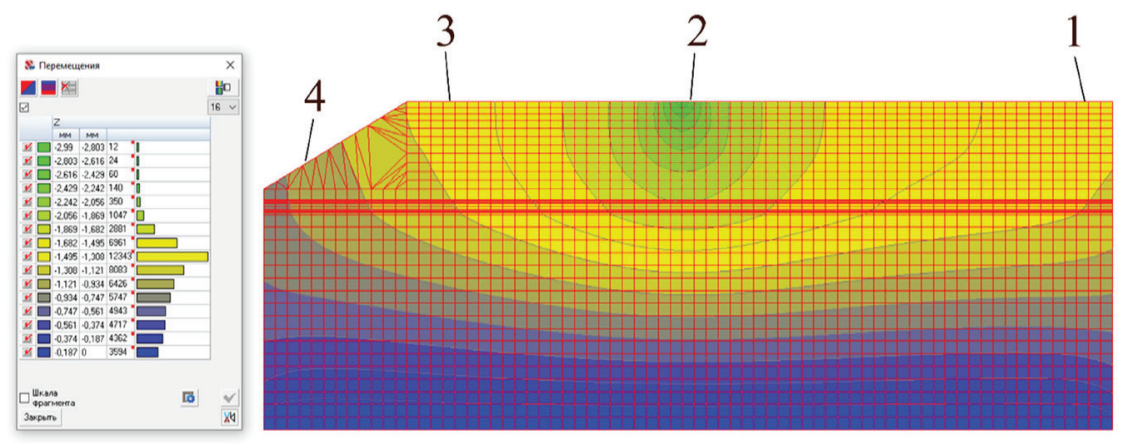

c

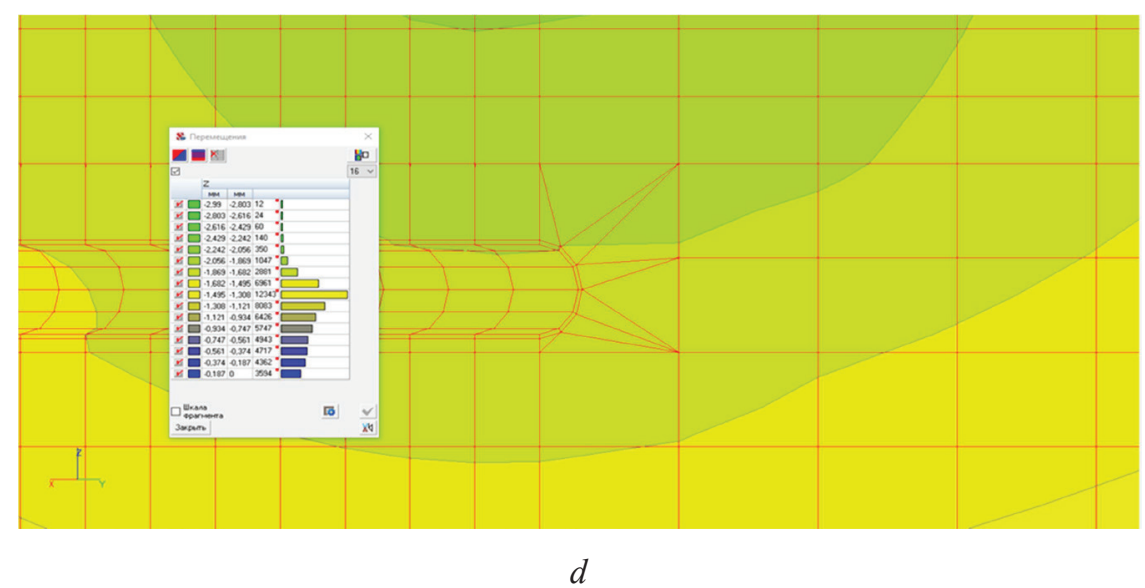

Fig. 3. Distribution of normal stresses $\mathrm{Nz}$ and deformations $\mathrm{Z}$ in a road structure with concrete pipe $(\mathrm{d}=100-118 \mathrm{~mm})$ from the action of a standard load of $57.5 \mathrm{kN}: a$-distribution of isopoles and isolines of stresses $\mathrm{Nz} ; b-\mathrm{a}$ fragment of the distribution of normal stresses $\mathrm{Nz}$ in the body of the drainage pipe; $c$ - distribution of deformations $Z ; d$ - a fragment of the distribution of deformations $\mathrm{Z}$ in the body of the drainage pipe; 1 - carriageway; 2 - load application; 3 -shoulders; 4 -slope 


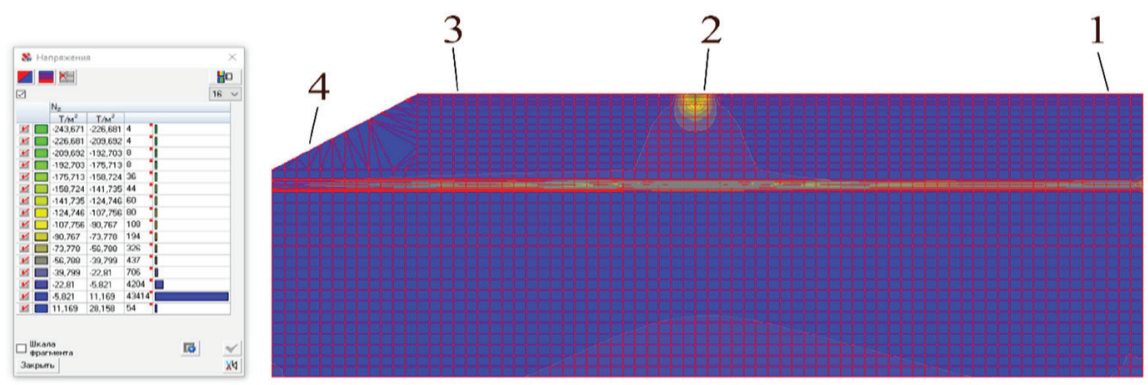

$a$

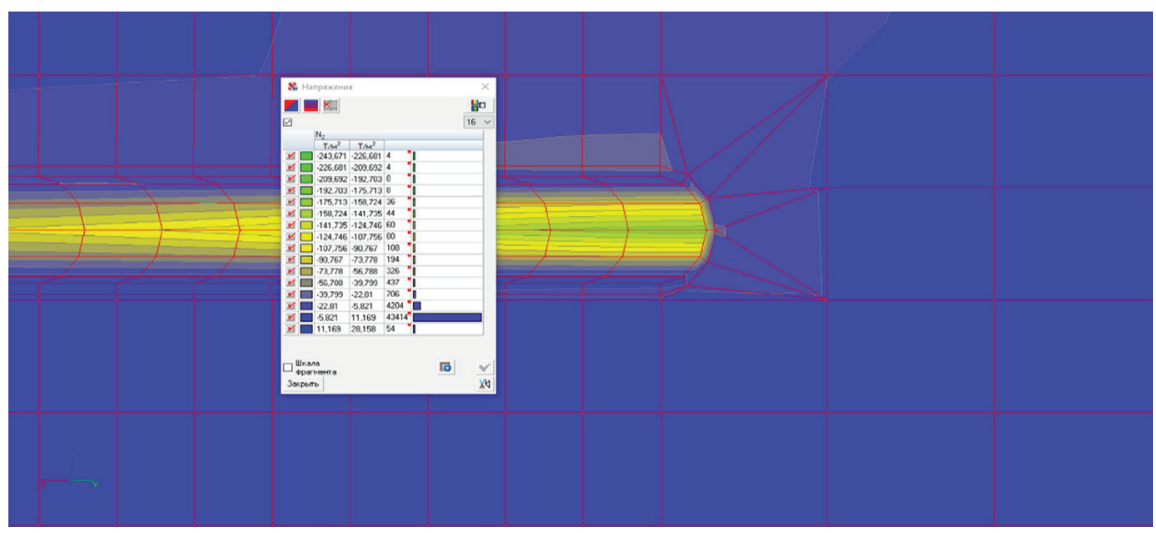

$b$

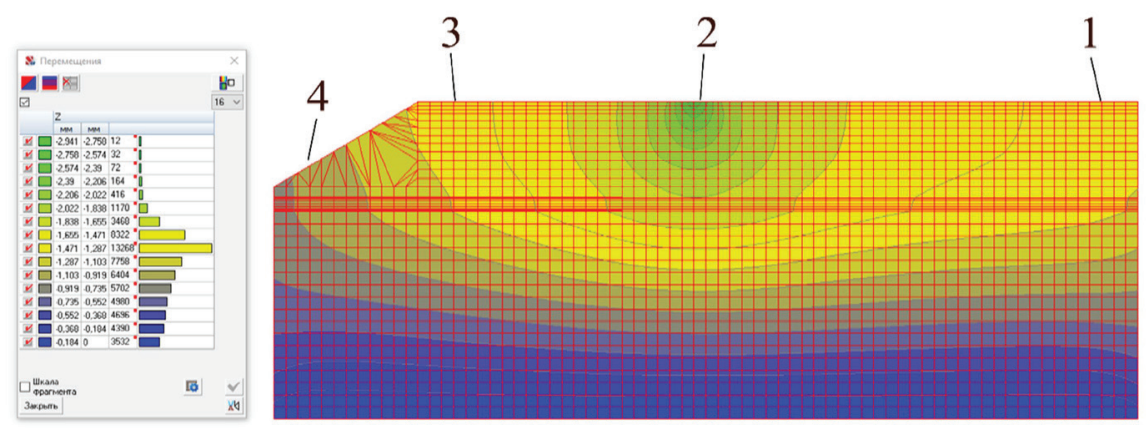

c

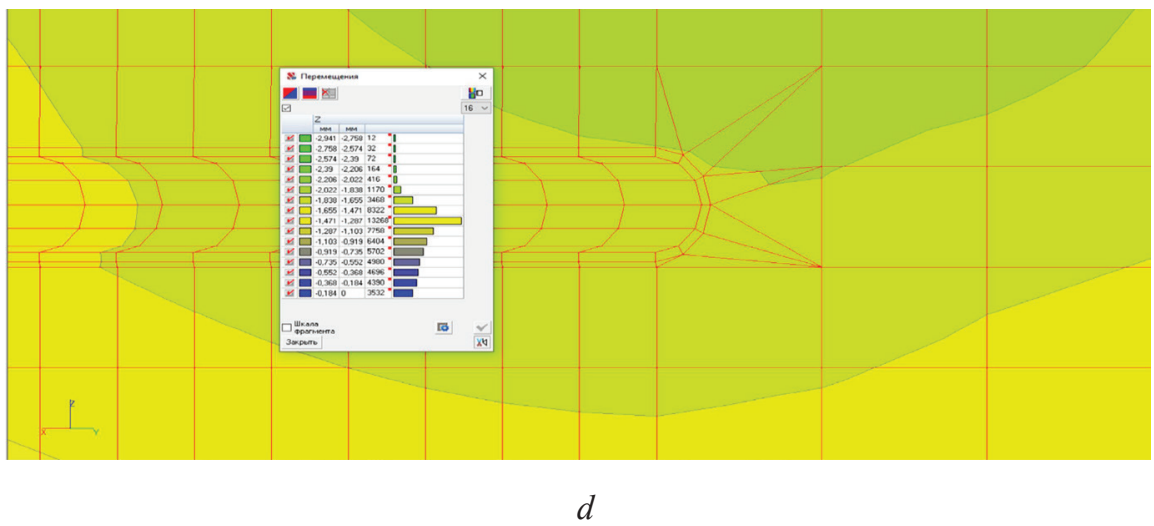

Fig. 4. Distribution of normal stresses $\mathrm{Nz}$ and deformations $\mathrm{Z}$ in a road structure with concrete pipe $(\mathrm{d}=100-118 \mathrm{~mm})$ from the action of a standard load of $86.25 \mathrm{kN}$ : $a$-distribution of isopoles and isolines of stresses $\mathrm{Nz} ; b-\mathrm{a}$ fragment of the distribution of normal stresses $\mathrm{Nz}$ in the body of the drainage pipe; $c$-distribution of deformations $Z ; d$-a fragment of the distribution of deformations $\mathrm{Z}$ in the body of the drainage pipe; 1 - carriageway; 2 - load application; 3 - shoulders; 4 - slope 
The values of normal stresses Nz in the body of a PVC pipe of the SN8 (SN4) type under standard and excess loads vary from $0.93 \mathrm{MPa}$ to $1.22 \mathrm{MPa}$, which corresponds to deformation indicators $\mathrm{Z}$ from $1.832 \mathrm{~mm}$ to $2.034 \mathrm{~mm}$. For a concrete pipe - Nz in the pipe body under standard and over-standard loads varies from 1.46 $\mathrm{MPa}$ to $1.55 \mathrm{MPa}$, which corresponds to deformation indicators $\mathrm{Z}$ from $2.056 \mathrm{~mm}$ to $2.206 \mathrm{~mm}$.

Deformations in the PVC pipe do not exceed $2 \%$, which is acceptable for the conditions of its operation. For concrete pipes, deformations are also less than $2 \%$, but it should be noted that they are generally not acceptable for such structural elements. This can lead to a violation of the integrity of the body of the pipe itself, the formation of cracks and, as a result, over time to deterioration in the operation of the entire drainage structure, a violation of the drainage function.

\section{Discussion}

As a rule, the solution to the problem of strength, stability and reliability of RS with tubular SD is not investigated. In work [6], the authors considered this problem using a simplified two-dimensional approach in PC SCAD. The deformation in the body of the pipes varies in the range of $0.11-0.13 \mathrm{~mm}$, in contrast to the obtained research results, which exceed the previous ones by 2 orders of magnitude. This is due to the difference between 2D and 3D modeling. Numerical modeling on the presented three-dimensional models made it possible to take into account the presence of tubular holes in a continuous layered $\mathrm{RC}$ under the influence of normative and excess loads. As structural elements of transverse tubular SD, it is advisable to use PVC pipes of class SN 8 or SN 4, in contrast to concrete pipes. Integrity violation of the concrete pipe will not contribute to drainage, but on the contrary the accumulation of moisture in the recreation center with the following negative consequences during the operation of a waterlogged section of the road. The proposed study raises an important question about the possibility of using new types of tubular drain materials that will provide the expected reliability in the absence of control over the passage of excess cargo on public roads. The results of the presented scientific work are the starting point for the development of standard design solutions for tubular sod in road structures, will be designed taking into account the passage of regulatory and excess cargo and ensure uninterrupted drainage functions.

In the future, the authors will carry out studies of RS with other SD types in order to determine their SSS in accordance with the real operating conditions of public highways.

\section{Conclusions}

RS models in volumetric elements with various types of DS tubular drains are constricted. Based on the results of numerical modeling, the distribution of normal stresses is obtained, on the basis of which deformations are determined in the transverse profile of the road and directly in the body of two types of drainage pipes. The resulting deformations in the body of PVC pipes are $1.8 \%$ of the outer diameter, which does not affect the drainage, unlike concrete pipes. Accordingly, it is most expedient to use PVC pipes of SN 8 or SN 4 class, which experience permissible deformations, even under excess load.

\section{References}

[1] Abou Rjeily, Y., Abbas, O., Sadek, M., Shahrour, I., Hage Chehade, F. (2017). Flood forecasting within urban drainage systems using NARX neural network. Water Science and Technology, 76 (9), 2401-2412. doi: http://doi.org/10.2166/wst.2017.409

[2] Bubela, A., Bondarenko, L., Chechuha, O., Slavinska, O. (2020). Research of the work of small drainage drainage on the intensity of drainage, taking into account the influence of vibration. Dorogi i Mosti, 2020 (21), 201-216. doi: http://doi.org/10.36100/ dorogimosti2020.21.201

[3] Yunianta, A., Suripin, Setiadji, B. H. (2019). Design of Sustainable Road Drainage System Model. Journal of Sustainable Engineering: Proceedings Series, 1 (1), 35-45. doi: http://doi.org/10.35793/joseps.vli1.5

[4] Mukherjee, D. (2014). Highway Surface Drainage System \& Problems of Water Logging In Road Section. The International Journal Of Engineering And Science, 3 (11), 44-51. Available at: http://www.theijes.com/papers/v3-i11/Version-1/ G031101044051.pdf 
[5] Gaidaichuk, V. V., Mozgovii, V. V., Zates, Iu. O., Shevchuk, L. V. (2017). Simulation of stress-strain states of road structures under action of transport loads. Strength of Materials and Theory of Structures, 99, 45-57. Available at: http://opir.knuba.edu. ua/zbirnyk-99/article-818

[6] Slavinska, O., Savenko, V., Bubela, A., Yaremov, A. (2018). Investigation of the work of the road construction at the sites by pipe drenes from materials of different origin. Eastern-European Journal of Enterprise Technologies, 2 (7 (92)), 18-26. doi: http://oi.org/10.15587/1729-4061.2018.126512

[7] Arkhitekturno-budivelni kreslennia (2015). Drenazhni konstruktsii zemlianoho polotna na avtomobilnykh dorohakh zahalnoho korystuvannia: AD A.2.4-37641918-002:2015. Ukravtodor, 37.

[8] Kazantsev, A. (2018). Search of mechanical properties of the road bed layers with a vibrating response of a road bed pavement. doi: http://doi.org/10.13140/RG.2.2.27747.60968

[9] Gavrilkina, A. O., Dremova, O. V., Mikhailov, V. S. (2017). Raschetnye modeli gruntovykh osnovanii, realizuemye v programmnom komplekse Scad Office. Polzunovskii almanakh, 4, 45-48. Available at: http://elib.altstu.ru/journals/Files/ pa2017_04_2/pdf/045gavrilkina.pdf

[10] Dovidnyk No. 1. Rozrakhunkovykh kharakterystyk gruntiv, materialiv pokryttia i osnovy dorozhnoho odiahu ta navantazhen vid transportnykh zasobiv (2017). UKRAVTODOR: HNADU, 39. http://online.budstandart.com/ua/catalog/doc-page.html? id_doc $=73497$ 